\title{
Clinical Spectrum and Management of Diabetic Ketoacidosis: Experience in A Tertiary Care Hospital
}

\author{
RAHIM MA ${ }^{\mathrm{a}}$, UDDIN KN ${ }^{\mathrm{b}}$, ZAMAN $\mathrm{S}^{\mathrm{c}}$, MUSA AKM ${ }^{\mathrm{d}}$, RAHMAN MR ${ }^{\mathrm{e}}$, HOSSAIN MD $^{\mathrm{f}}$, AHMED AKMS ${ }^{\mathrm{f}}$, \\ AHMED JU' ${ }^{\mathrm{a}}$, SAMAD T ${ }^{\mathrm{g}}$, HAQUE HF${ }^{\mathrm{g}}$, DEWAN Pg, SARKER RSC ${ }^{\mathrm{g}}$, DASTIDAR $\mathrm{S}^{\mathrm{h}}$
}

\begin{abstract}
Background: Diabetic ketoacidosis (DKA) is an acute metabolic complication of diabetes mellitus (DM). It may be the presenting feature in type $1 \mathrm{DM}$, but more commonly it complicates previously diagnosed diabetic patients, both type 1 and type 2. If not recognized early and treated in a judicious way the outcome is often fatal.

Objectives: The objectives of this study was to see the common presenting features of DKA, their precipitating causes, patterns of electrolyte imbalance, treatment requirement in early hours and to see the outcome.
\end{abstract}

Materials and methods: This cross sectional study was done in BIRDEM General Hospital on fifty adult patients who presented with DKA over a period of nine months (January 2007 to September 2007).

Results: Total number of patients were 50, male were 24 and female were 26 (M:F =12:13). Mean age was $27.6 \pm$ 3.7 years. The incidence of DKA was more in known diabetic patients (32, 64\%), in comparison with new cases $(18,36 \%)$.

a. Rahim MA, Ahmed JU, Registrar, Internal Medicine, Ibrahim Medical College and BIRDEM General Hospital, Shahbag, Dhaka-1000, Bangladesh.

b. Uddin KN, Professor and Head, Internal Medicine, Ibrahim Medical College and BIRDEM General Hospital, Shahbag, Dhaka-1000, Bangladesh.

c. Zaman S, Assistant Registrar, Cardiology, NICVD, Sher-eBangla Nagar, Dhaka-1207, Bangladesh.

d. Musa AKM, Associate professor, Internal Medicine, Ibrahim Medical College and BIRDEM General Hospital, Shahbag, Dhaka-1000, Bangladesh.

e. Rahman MR, Associate Professor and Resident Physician, Ibrahim Medical College and BIRDEM General Hospital, Shahbag, Dhaka-1000, Bangladesh.

f. Hossain MD, Ahmed AKMS, Assistant Professor, Internal Medicine, Ibrahim Medical College and BIRDEM General Hospital, Shahbag, Dhaka-1000, Bangladesh.

g. Samad T, Haque HF, Dewan P, Sarker RSC, Senior Medical Officer, Internal Medicine, BIRDEM General Hospital, Shahbag, Dhaka-1000, Bangladesh.

h. Dastidar S Medical Officer, Reproductive and Child Health Department, NIPSOM, Mohakhali, Dhaka-1212, Bangladesh.

Address of Correspondence: Dr. Muhammad Abdur Rahim, FCPS (Medicine), Registrar, Department of Internal Medicine, Ibrahim Medical College and BIRDEM General Hospital, Shahbag, Dhaka1000, Bangladesh. E-mail: armurad_1976@yahoo.co.in.

Received: May 20, 2011

Accepted: June 29, 2011
Frequency was more in poor village people (31, 62\%). Vomiting (24, 48\%) was the most frequent complaint, followed by fever (19, 38\%), nausea (16,32\%), abdominal pain $(14,28 \%)$, weakness $(13,26 \%)$, polyuria $(12,24 \%)$ and polydypsia $(8,16 \%)$. Infection $(18,36 \%)$ was the most common precipitating cause, closely followed by inadherence to insulin therapy (17, 34\%). In 12 (24\%) cases no cause could be identified. Glycaemic control was poor, HbA1c was $>7 \%$ in $98 \%$ cases. Severe acidosis $(\mathrm{pH}<7)$ was less common $(4,8 \%)$ and gross electrolyte imbalance was uncommon but all patients required potassium supplementation in course of treatment. Neutrophilic leukocytosis was present in 44 (88\%) cases, irrespective of presence of infection. Mortality was low $(3,6 \%)$.

Conclusion: Diagnosis and treatment of DKA is not difficult if recognized early. So, high index of suspicion is necessary, particularly in previously undiagnosed cases.

Key wards: Diabetic Ketoacidosis, Diabetes Mellitus.

(Birdem Med J 2011; 1(1): 15-20)

\section{Introduction}

Diabetic ketoacidosis is a medical emergency. It may be the presenting feature of type 1 diabetes, but more frequently it occurs in established diabetic patients- both type 1 and type 2 . The cardinal biochemical features of diabetic ketoacidosis are hyperglycaemia, hyperketonaemia and metabolic acidosis ${ }^{1}$. Alberti's definition $^{2}$ describes 'severe uncontrolled diabetes requiring emergency treatment with insulin and intravenous fluids with a blood ketone body ( acetoacetate and 3-hydroxybutyrate ) concentration of greater than $5 \mathrm{~m}$.mol per litre'. For practical purpose, diagnostic criteria often includes a plasma bicarbonate concentration of $15 \mathrm{~m} . \mathrm{mol}$ per litre or less with significant ketosis (urine ketostix reaction at least ++ or plasma ketostix reaction + or more) in a patient with high blood glucose. American Diabetic Association (ADA) has given a guideline ${ }^{3}$ of assessing severity of diabetic ketoacidosis and it's differentiation from hyperglycaemic hyperosmolar state (HHS). 
The presence of no or near no insulin is the critical underlying defect in the pathogenesis of DKA coupled with increased quantity of counter regulatory hormones. Insulin deficiency leads to hyperglycaemia, which in turn causes osmotic diuresis and dehydration. Withdrawal of insulin from insulin dependent patients lead to an early rise of plasma glucagon ${ }^{2}$ resulting in increased fat metabolism and production of ketone bodies. As hyperglycaemia and ketoacidosis develop, dehydration and acidosis stimulate the release of catecholamines ${ }^{4}$ and cortisol $^{5}$, leading to a vicious circle in which worsening metabolic decompensation stimulates further secretion of catabolic hormones. In moderate DKA, average 6 litres of fluid, $500 \mathrm{~m} . \mathrm{mol}$ $\mathrm{Na}, 400 \mathrm{~m} . \mathrm{mol} \mathrm{Cl}$ and $350 \mathrm{~m}$. mol K are lost. ${ }^{1}$

Most patients present with polyuria, polydipsia, nausea, vomiting, generalized weakness and weight loss. Abdominal pain is a recognized feature, particularly in children. Patients are frequently dehydrated, hypotensive, tachycardic and dyspneic. Ultimately they become comatose. Features of infection may be present.

Precipitating causes of diabetic ketoacidosis include infection $30 \%$, errors in management $15 \%$, newly diagnosed diabetes $10 \%$, other identifiable medical disease $5 \%$ and in $40 \%$ cases no cause is found ${ }^{6}$. Drugs e.g. corticosteroids, thiazides and sympathomimetics are often the culprits ${ }^{3}$.

The diagnosis of diabetic ketoacidosis is simple if it is considered in the differentials. A urine sample showing marked glycosuria and ketonuria or an undiluted plasma sample giving a strongly positive result in nitroprusside test for acetoacetate is sufficient for diagnosis. These common tests are often not done and there occurs delay in diagnosis. Differential diagnoses includes hyperglycaemic hyperosmolar state(HHS), lactic acidosis, other causes of metabolic acidosis like uraemia, salicylates, methanol, ethyline glycol poisoning etc.

Investigations include plasma glucose, blood urea, serum creatinine, serum electrolytes, serum osmolality, urinalysis, urine or plasma ketones and arterial blood gas analysis. Bacterial cultures of urine, blood, throat swabs and chest $\mathrm{X}$-ray are often required.

Successful treatment of DKA requires correction of dehydration, hyperglycaemia, electrolyte imbalance, identification of precipitating cause and it's treatment and above all frequent monitoring ${ }^{1}$. Use of flow chart documenting clinical status (blood pressure, intakeoutput chart and level of consciousness, if necessary), blood glucose, electrolytes and anion gap is recommended ${ }^{7}$.

The common complications of DKA and it's treatment are hypoglycaemia, hypokalaemia and hyperglycaemia. Cerebral oedema is a rare but fatal complication, occurring in $0.7-1.0 \%$ children with DKA with mortality rate $>70 \%$, with only $7-14 \%$ patients recovering without permanent morbidity ${ }^{3}$. Hypoxemia and rarely noncardiogenic pulmonary oedema may complicate treatment of DKA. Thromboembolic complications, DIC and rarely rhinocerebral mucormycosis can occur in diabetic patients with ketoacidosis ${ }^{2}$.

The average mortality rate for ketoacidosis in developed countries is currently estimated $5-10 \%$, although reported rates vary greatly ${ }^{8}$. Mortality is greatly higher in less specialized centers and in elderly population ${ }^{9}$.

Many cases of DKA can be prevented by better access to medical care, proper education and effective communication with the health care provider during an intercurrent illness ${ }^{3}$.

\section{Materials and methods}

This cross sectional study was done in the Department of Medicine, BIRDEM General Hospital, Dhaka. Data were collected from fifty hospitalized patients with a diagnosis of DKA who were admitted and managed in general medical wards. The study period was nine months (January 2007 to September 2007). All adult patients aged 18 years and above with a diagnosis of DKA, whether previously known diabetic or newly diagnosed case were included in the study. Patients having other causes of acidosis like chronic kidney disease (CKD), those who required transfer to Critical Care Units for treatment and those who were below the age of 18 years were excluded from the study.

\section{Results}

Total number of cases were 50, male were 24 and female were 26, M:F ratio was 12:13. Mean age was $27.6 \pm 3.7$ years. Thirty one (62\%) patients came from villages and 19 (38\%) patients were from urban and sub-urban areas. Most (47, 94\%) of the patients were from family of low income group. Eighteen patients (36\%) were detected as diabetic first time at this admission (new case) and 32(64\%) patients were known diabetic (old 
case). Among the 32 known diabetic patients, 24 (75\%) patients were on insulin, 7 (21.88\%) patients were on oral anti-diabetic agents (OAD), and 1 (3.13\%) patient was on medical nutrition therapy (MNT). (Figure 1)

The common presenting features were vomiting (26, $52 \%)$, fever (19, 38\%), nausea (16, 32\%), abdominal pain $(14,28 \%)$ (including epigastric pain in 4 cases, suprapubic pain in 3 cases, right hypochondriac pain in 2 cases and non-specific pain in 5 cases), polyuria (12, $24 \%$ ) and polydipsia (8, 16\%). Other features were relatively less common. Five (10\%) patients had diabetic foot (2 cases had gangrene of one or more toes, 2 cases had abscess on dorsum of foot and 1 case had infection of amputated stump of leg) and $1(2 \%)$ patient had cellulitis and thrombophlebitis involving fore arm. Out of 50 cases, 4 (8\%) cases had repeated history of hospitalization with DKA.

All patients had hyperglycaemia (Figure 2), almost all 49 (98\%) had HbA1C > 7\%.(Table I)

Thirty seven (74\%) patients had +++ acetonuria and 13 (26\%) patients had ++ acetonuria at the time of admission. In a significant number of patients acetonuria persisted for a longer time compared with clinical and biochemical improvement of the patients evidenced by $\mathrm{pH}$ and bicarbonate levels. Thirty (60\%) patients had moderate metabolic acidosis, 16 (32\%) had mild metabolic acidosis and 4(8\%) patients had severe metabolic acidosis (ADA criteria) ${ }^{3}$. (Figure 3)

Infection was the commonest (18, 36\%) precipitating cause, followed by inadherence to insulin therapy (17, 34\%). Pancreatitis precipitated DKA in 3 (6\%) cases, and in 12 (24\%) cases no cause was identified. (Figure 4)

Most of the patients had normal $\mathrm{Na}$ and $\mathrm{K}$ levels at presentation and only three (6\%) patients had severe hyponatraemia and hypokalaemia (Table II). All patients developed hypokalaemia within twelve hours of admission during the process of correction of metabolic acidosis with treatment (with intravenous fluids and insulin) and in all patients IV replacement of potassium was given.

Six (12\%) patients had normal total white cell count (4000-11000/cmm of blood), in 17(34\%) cases white cell count was between 11000-15000/cmm of blood and in 27 (54\%) cases total white cell count was > 15000/ $\mathrm{cmm}$ of blood, though infection was present only in 18(36\%) cases.
During the first 24 hours of in-hospital treatment, each patient required, on an average of 4.12 litres of intravenous fluids, $60 \mathrm{~m}$.mol of potassium and 72 units of insulin.

Most patients $(47,94 \%)$ recovered from the acute crisis and only $3(6 \%)$ patients expired within 48 hours of admission.

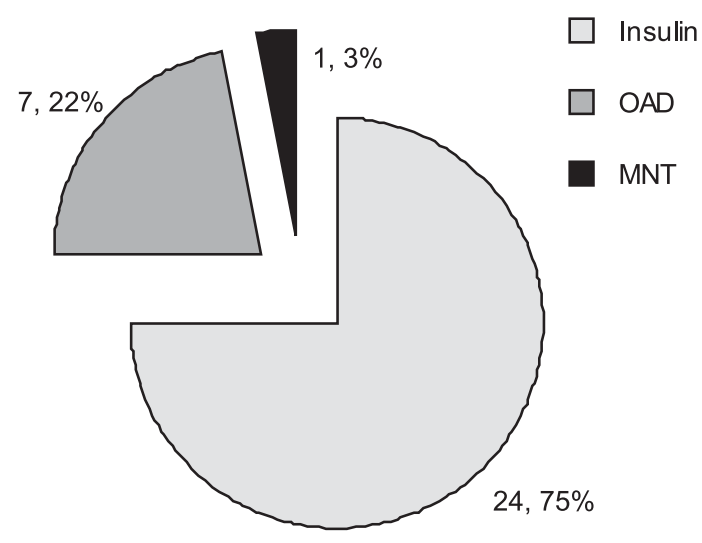

Fig.-1: Distribution of cases according to present treatment in known diabetic patients (Total 32)

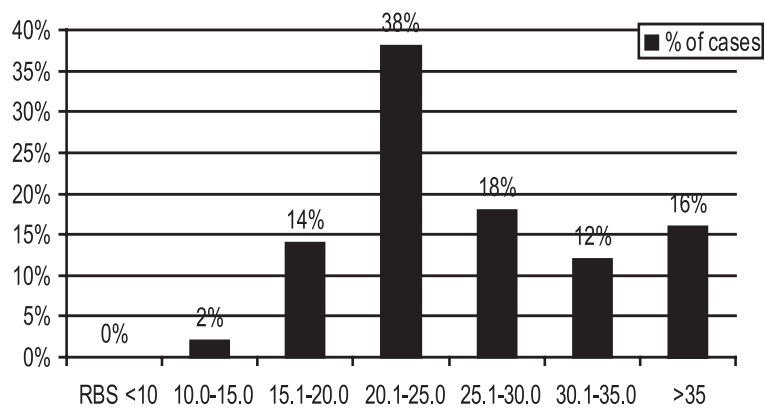

Fig.-2: Distribution of patients according to random blood glucose level (RBS m.mol/L) at presentation

Table I

Distribution of patients according to HbA1C level

\begin{tabular}{lcc} 
HbA1C (\%) & Number of Patients & Percent \\
\hline$<7$ & 1 & 2 \\
$7-8.5$ & 9 & 18 \\
$8.6-10$ & 24 & 48 \\
$>10$ & 16 & 32 \\
\hline
\end{tabular}




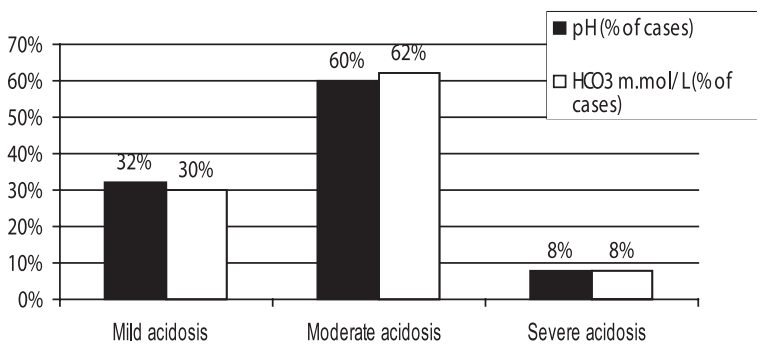

Fig-3: Distribution of patients according to severity of DKA (ADA criteria)

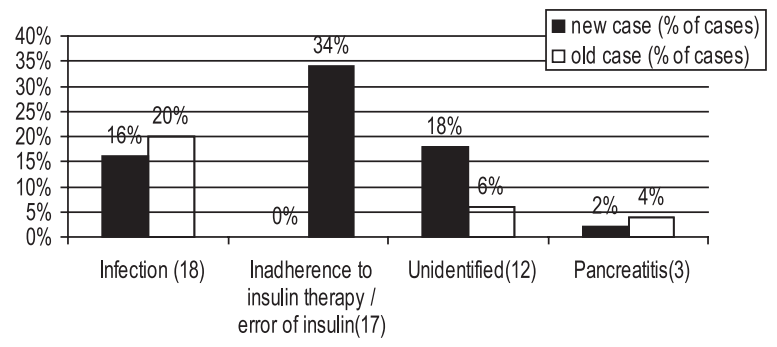

Fig.-4: Distribution of cases according to precipitating causes

Table-II

Distribution of patients according to serum sodium and potassium levels at presentation

\begin{tabular}{lcc}
$\begin{array}{l}\text { Serum sodium } \\
(\mathrm{m} . \mathrm{mol} / \mathrm{L})\end{array}$ & $\begin{array}{c}\text { Number of } \\
\text { Patients }\end{array}$ & Percent \\
\hline$<120$ & 3 & 6 \\
$121-125$ & 2 & 4 \\
$126-130$ & 9 & 18 \\
$131-135$ & 6 & 12 \\
$136-140$ & 20 & 40 \\
$141-145$ & 6 & 12 \\
$146-150$ & 4 & 8 \\
$>150$ & 0 & 0 \\
Serum potassium (m.mol/L) & & \\
$<3$ & 3 & 6 \\
$3-4.5$ & 20 & 40 \\
$4.6-6$ & 21 & 42 \\
$>6$ & 6 & 12 \\
\hline
\end{tabular}

\section{Discussion}

This study was done to see the common presenting features of diabetic ketoacidosis, their precipitating causes, the glycaemic control of these patients, electrolyte disturbances at presentation and their correction in first 24 hours and the outcome in BIRDEM General Hospital, a tertiary care hospital. The study was carried out on hospitalized adult patients aged 18 years and above. Total number of patients were 50 . Among them, 32 (64\%) patients were already diagnosed as diabetic and 18 (36\%) patients were diagnosed diabetic first time during this admission. There was slight female predominance, female : male ratio was 13:12. Most patients were from villages and many were of lower socio-economic group. Female: male ratio in Denmark ${ }^{10}$ was $7.2: 5.7$. In a study in Taipei ${ }^{11}$, it was found that $67 \%$ DKA patients were female. In a small series of paediatric patients in India ${ }^{12}$ female: male ratio was 1:2.

Surprisingly, the typical features of polyuria, polydipsia and weight loss which are the predominant features of DKA, were relatively less common than nausea, vomiting and abdominal pain. Vomiting $(24,48 \%)$ was the most frequent symptom. Features of infection e.g. fever, cough, urinary symptoms and diabetic foot infection were also common.

Infection (18, 36\%) was the commonest precipitating cause in this study. In 17 (34\%) cases DKA was precipitated by omission or error in insulin management. In 12 (24\%) cases no cause was found and pancreatitis precipitated DKA in 3 (6\%) cases. In different studies, it was found that infection and drug non-compliance were the most common precipitating causes and these two collectively comprised $70-90 \%$ causes. In a study in Nairobi ${ }^{13} 34 \%$ cases were precipitated by omitting insulin, 23.4\% cases had infection. Non-compliance was the most common cause in Korea ${ }^{14}$, whereas in another study in Pakistan ${ }^{15}$, infection precipitated DKA in 63\% cases of type 2 diabetes mellitus.

Of the 50 cases studied, 30 (60\%) had moderate metabolic acidosis, 16 (32\%) had mild metabolic acidosis. The remaining 4 (8\%) cases had severe metabolic acidosis. Most patients had grossly elevated HbA1c, 24 (48\%) cases had HbA1c > 8.5\%, 16 (32\%) cases had $\mathrm{HbA} 1 \mathrm{c}>10 \%$. In a study in Nairobi ${ }^{13}>90 \%$ patients had HbA1c $>8 \%$.

In this study, most patients with mild to moderate acidosis did not have gross electrolyte imbalance. Most had normal or slightly low $\mathrm{Na}+$ levels, high normal or slightly elevated $\mathrm{K}+$ levels. Similar results were found in a study in Pakistan ${ }^{15}$. Three patients had severe 
hyponatraemia and hypokalaemia, but after initiation of treatment with intravenous fluid and insulin, all patients developed hypokalaemia requiring intravenous correction. In a National Survey of Denmark ${ }^{16}$, similar observation was found.

Most patients had grossly elevated blood sugar levels and ++ or more ketonuria on urine ketostix test. Patients were found to have ketonuria for longer period in comparison with their clinical and biochemical improvement evidenced by $\mathrm{pH}$ and $\mathrm{HCO}^{-}$levels. Similar observation was reported in a small study in India $^{12}$.

Forty four (88\%) patients had neutrophilic leukocytosis. Among these 44 patients, only 18 patients had infection. In another study ${ }^{13}>65 \%$ patients had leucocytosis and in $55 \%$ patient there was no infection.

The outcome, in terms of in-hospital mortality (in general medical wards), was quiet satisfactory. Only 3 (6\%) patients expired within 48 hours of admission and these patients had severe acidosis with gross hyponatraemia and hypokalaemia at presentation. Among them, two patients were treated initially in less specialized hospitals, one had acute pancreatitis, one patient was grossly neglected diabetes mellitus and had history of repeated admissions with DKA. All other patients recovered. In the $\mathrm{UK}^{17}$, in-hospital mortality rate was upto $14 \%$ because of variations in management and various other factors, in Denmark ${ }^{16}$ it was $4 \%$ and in Korea ${ }^{14}$, in-hospital mortality was $11.8 \%$. In Nairobi ${ }^{13} 29.8 \%$ patients expired in hospital within 48 hours of admission.

\section{Conclusion}

In this cross-sectional observational study of fifty adult diabetic ketoacidosis patients (treated in general medical wards) in BIRDEM General Hospital, it was found that DKA occurred more commonly in known diabetic patients who were non-compliant to insulin treatment or who had had infection. New cases were not uncommon. Polyuria, polydypsia, vomiting, abdominal pain and infection were common features. The glycaemic control in these patients was poor. Severe metabolic acidosis was less common. In mild to moderate acidosis, gross electrolyte disturbances were infrequent but hypokalaemia developed after initiation of treatment. Leukocytosis was common, even in absence of infection and ketonuria persisted with treatment in spite of clinical and biochemical improvement. The overall outcome was comparable with developed countries. (The only limitation of the study was that, those patients who required treatment in Critical Care Units were not included in this study).

\section{Acknowledgement}

I am indebated to Professor Mohammad Omar Faruq, Head of Critical Care Medicine of BIRDEM General Hospital for many valuable suggestions and comments in the process of preparation of this manuscript.

\section{References}

1. Frier BM, Fisher M. Diabetes Mellitus. In: Boon NA, Colledge NR, Walker BR, Hunter JAA editors. Davidson’s Principles \& Practice of Medicine. 20 $0^{\text {th }}$ ed. Edinburgh: Churchil Livingstone.2006.p820-2.

2. Krentz AJ, Nattrass M. Acute Metabolic Complications of Diabetes: Diabetic Ketoacidosis, Hyperosmolar non-ketotic Hyperglycaemia and Lactic acidosis. In: Pickup JC, Williams G editors. Textbook of Diabetes. $3^{\text {rd }}$ ed. vol 1 Massachussetts: Blackwell Science Ltd.2003.p32.2-15.

3. Diabetes Care. 2007 Jan; 30 (1 supl): s109-16.

4. Christensen NJ. Plasma norepinephrine and epinephrine in untreated diabetics during fasting and after insulin administration. Diabetes 1974;23:1-8.

5. Jacobs JS, Nabarro JDN. Plasma 11-hydroxycorticosteroid and growth hormone levels in acute medical illnesses. BMJ 1969;2:595-8.

6. Nattrass M. Diabetic Ketoacidosis. Medicine International. Oxford: The Medicine Publishing Company Elsevier Ltd. 2006 Nov; (1) :105.

7. Wyckoff J, Abrahamson MJ. Diabetic Ketoacidosis and Hyperosmolar Hyperglycaemoc state. In: Kahn CR, Weir GC, King GL, Jacobson AM, Moses AC, Smith RJ editors. Joslin's Diabetes Mellitus. $4^{\text {th }}$ ed. Bosston: Joslin's Diabetes Center.2005.p896.

8. Schade DS, Eaton RP, Alberti KGMM, Johnston DG. Diabetic Coma, Ketoacidotic and Hyperosmolar. Albuquerque: University of New Mexico Press,1981.

9. Gale EAM, Dornan TL, Tattersall RB. Severely uncontrolled diabetes in the over-fifties. Diabetilogia 1981;21:25-8.

10. Henriksen OM, Roder ME, Prahl JB, Svendsen OL. Diabetic ketoacidosis in Denmark: incidence and mortality from public health registries. Diabetes Res Clin Pract.2007 Apr; 76 (1) :51-6.

11. Lin SF, Lin JD, Huang YY. Diabetic ketoacidosis: comparisons of patient characteristics, clinical presentations and outcomes today and 20 years ago. Chang Gunh Med J.2005 Jan; 28 (1) : 24-30. 
12. Jahagirdar RR, Khadilkar VV, Khadilkar AV, Lalwani SK. Management of diabetic ketoacidosis in PICU. Indian J Pediatr.2007 Jan; 74 (6):551-4.

13. Mbugua PK, Otieno CF, Kayima JK, Amayo AA, McLigeyo SO. Diabetic ketoacidosis: clinical presentation and precipitating factors at Kenyatta National Hospital, Nairobi. East Afr Med J.2005 Dec; 82 (12 supl): s191-6.

14. Ko SH, Lee WY, Lee JH, Kwon HS, Lee JM, Kim SR, Moon SD, Song KH, Han JA, Ahn YB, Yoo SJ, Son HY. Clinacal characteristics of diabetic ketoacidosis in Korea over the past two decades. Diabet Med. 2005 Apr; 22 (4): 466-9.
15. Jabbar A, Farooqui K, Habib A, Islam N, Haque N, Akhter J. Clinical characteristics and outcomes of diabetic ketoacidosis in Pakistani adults with type 2 diabetes mellitus. Diabet Med. 2004 Aug; 21 (8) : 920-3.

16. Henriksen OM, Prahl JB, Roder ME, Svendsen OL. Treatment of diabetic ketoacidosis in adults in Denmark: a national survey. Diabetes Res Clin Pract. 2007Jul; 77 (1) : 113-9.

17. Sharma V, Hadebe N. Diabetic ketoacidosis: principles of management. Br J Hosp Med (Lond). 2007 Apr; 68 (4): 1849. 